\title{
Differential expression of fatty acid-binding proteins and pathological implications in the progression of tongue carcinoma
}

\author{
YOSHITO OHYAMA ${ }^{1}$, YUKIHIRO KAWAMOTO ${ }^{1}$, TADASHIGE CHIBA ${ }^{2}$, \\ KENTARO KIKUCHI $^{3}$, HIDEAKI SAKASHITA ${ }^{1}$ and KAZUSHI IMAI ${ }^{2}$ \\ ${ }^{1}$ Division of Oral and Maxillofacial Surgery 2, Department of Diagnostic and Therapeutic Science, School of Dentistry, \\ Meikai University, Sakado, Saitama 3500283; ${ }^{2}$ Department of Biochemistry, School of Life Dentistry at Tokyo, \\ The Nippon Dental University, Tokyo 1028159; ${ }^{3}$ Division of Pathology, Department of Diagnostic and Therapeutic Science, \\ School of Dentistry, Meikai University, Sakado, Saitama 3500283, Japan
}

Received July 10, 2013; Accepted September 12, 2013

DOI: $10.3892 / \mathrm{mco} .2013 .198$

\begin{abstract}
Tongue carcinomas are common malignancies of the oral cavity. Understanding the molecular mechanisms behind the disease progression is a prerequisite for improving patient prognosis. Fatty acid-binding proteins (FABPs) are cytoplasmic lipid chaperones that affect cellular organization and energy production. Although their aberrant expression is involved in carcinoma progression, its role in the pathology of tongue carcinomas remains unclear. In the present study, the immunohistochemical expression of FABP4 and FABP5 in tongue carcinomas $(n=58)$ and its involvement in the clinicopathological parameters were examined. Normal tongue epithelial cells expressed FABP5, an epidermal-type FABP, but not FABP4, an adipocyte-type FABP. The cytoplasmic staining of FABP5 was increased in carcinomas with advanced T-stage $(\mathrm{P}<0.05)$ and clinical stage $(\mathrm{P}<0.05)$. Ectopic expression of FABP4 was detected in almost all carcinomas, although its role in disease progression remains undetermined. Upregulation of FABP5 in the wounded skin of genetically normal mice indicated that microenvironmental tissue factors induce FABP5 expression. The results of the present study demonstrated the aberrant expression of FABP4 and FABP5 in tongue carcinomas and suggested the involvement of FABP5 in disease progression.
\end{abstract}

\section{Introduction}

Squamous cell carcinoma developing from the oral cavity is a common malignant neoplasm of the head and neck, with tongue carcinomas accounting for $25-40 \%$ of all oral carcinomas $(1,2)$. Over $50 \%$ of patients experience a relapse and the

Correspondence to: Professor Kazushi Imai, Department of Biochemistry, School of Life Dentistry at Tokyo, The Nippon Dental University, 1-9-20 Fujimi, Chiyoda-ku, Tokyo 1028159, Japan

E-mail: kimai@tky.ndu.ac.jp

Key words: fatty acid-binding protein, progression, tongue carcinoma incidence is expected to increase in the next few decades (3). Carcinoma cells exhibit marked changes in cellular composition, signaling and energy metabolism, and these changes lead to advanced stages of progression $(4,5)$. Identification of molecular aspects of carcinoma cells contributes to the development of novel therapeutic approaches and improves patient prognosis.

Carcinoma cells change the lipid composition of cell membranes (6) and stimulate lipid metabolism during tumor progression (7). Fatty acid-binding proteins (FABPs) are the lipid chaperones that transport long chain fatty-acids (LCFAs) to specific cell compartments, such as lipid droplets for storage; the endoplasmic reticulum for signaling, trafficking and membrane synthesis; mitochondria or peroxisomes for oxidation; cytosoles or other enzymes for activity regulation; the nucleus for gene transcription; or even outside of the cells in order to signal in an autocrine or paracrine manner $(8,9)$. The FABP family consists of at least nine members that were originally identified in different cell or tissue types, such as FABP4 in adipocytes and FABP5 in the epidermis $(10,11)$. Studies have revealed the involvement of aberrant FABP expression in the pathology of various diseases including malignant neoplasms $(8,9)$. Although FABP5 is reported to be upregulated in oral carcinomas, its involvement in disease progression remains controversial (11-13).

The ectopic expression of FABP4 in carcinomas of the stomach (14) and ovary (15) facilitates disease progression, whereas it is downregulated in aggressive subsets of bladder and breast carcinomas (16-18). These data suggest the differential role of FABP4 in carcinomas depending on the tissue origin. FABP4 expression in oral carcinomas requires elucidation. Therefore, in this study, we examined FABP4 and FABP5 expression in tongue carcinomas by immunohistochemistry, and analysed their involvement in disease progression.

\section{Materials and methods}

Patient population. A total of 58 cases of tongue carcinomas obtained at incisional biopsy or surgery at Meikai University Hospital (Sakado, Japan) from 1990 to 2010 were examined. The patients were comprised of 34 males and 24 females, with 
Table I. Fatty acid-binding protein 5 staining score and clinicopathological parameters.

\begin{tabular}{|c|c|c|c|c|c|}
\hline \multirow[b]{2}{*}{ Parameters } & \multirow[b]{2}{*}{ No. } & \multicolumn{2}{|c|}{ Nucleus } & \multicolumn{2}{|c|}{ Cytoplasm } \\
\hline & & Mean \pm SD & P-value & Mean \pm SD & P-value ${ }^{a}$ \\
\hline Age (years) & & & 0.220 & & 0.553 \\
\hline$<65$ & 33 & $4.969 \pm 2.495$ & & $8.188 \pm 2.571$ & \\
\hline$\geq 65$ & 25 & $5.120 \pm 3.180$ & & $8.120 \pm 3.206$ & \\
\hline Gender & & & 0.491 & & 0.411 \\
\hline Female & 24 & $4.125 \pm 2.153$ & & $7.542 \pm 3.036$ & \\
\hline Male & 34 & $5.697 \pm 3.036$ & & $8.606 \pm 2.645$ & \\
\hline T-stage ${ }^{b}$ & & & 0.137 & & 0.125 \\
\hline $\mathrm{T} 1$ & 38 & $4.842 \pm 2.666$ & & $7.553 \pm 2.617$ & \\
\hline $\mathrm{T} 2$ & 18 & $4.824 \pm 2.580$ & & $9.059 \pm 2.968$ & \\
\hline $\mathrm{T} 4$ & 2 & $10.500 \pm 2.121$ & & $12.000 \pm 0.000$ & \\
\hline $\mathrm{N}$-stage ${ }^{\mathrm{b}}$ & & & 0.482 & & 0.764 \\
\hline No & 49 & $5.021 \pm 2.809$ & & $7.979 \pm 2.779$ & \\
\hline N1 & 6 & $4.000 \pm 1.265$ & & $9.167 \pm 3.488$ & \\
\hline $\mathrm{N} 2$ & 3 & $7.333 \pm 4.163$ & & $9.000 \pm 3.000$ & \\
\hline Clinical stage ${ }^{b}$ & & & 0.720 & & 0.619 \\
\hline 1 & 38 & $4.842 \pm 2.666$ & & $7.553 \pm 2.617$ & \\
\hline 2 & 10 & $5.333 \pm 3.354$ & & $9.333 \pm 2.958$ & \\
\hline 3 & 6 & $4.000 \pm 1.265$ & & $9.167 \pm 3.488$ & \\
\hline 4 & 4 & $7.750 \pm 3.500$ & & $9.750 \pm 2.872$ & \\
\hline Histological differentiation & & & 0.463 & & 0.161 \\
\hline Well & 32 & $5.469 \pm 2.771$ & & $8.189 \pm 2.856$ & \\
\hline Moderate & 20 & $4.450 \pm 2.395$ & & $7.750 \pm 2.899$ & \\
\hline Poor & 6 & $4.600 \pm 4.334$ & & $9.600 \pm 2.510$ & \\
\hline
\end{tabular}

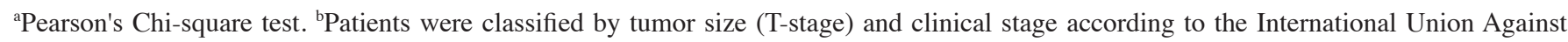
Cancer World Health Organization grading system and by the stage of lymph node metastasis (N-stage).

an age range of $29-92$ years (mean $\pm \mathrm{SD}, 62.8 \pm 14.9$ years) at the time of diagnosis. The details of pretreatment clinical and pathological characteristics are provided in Table I. Histologic grading and staging were assessed according to the International Union Against Cancer (UICC) tumor-node-metastasis classification. Tissues were obtained subsequent to the written consent of the patient and with the approval of the Ethics Committee of the Institutional Review Boards of Meikai University.

Mouse skin wounds. Mouse skin wound tissues were obtained as previously described (19). Briefly, $2 \mathrm{~cm}$ long full-thickness skin incisions were created on the dorsum of C57BL/6 female mice. The mice were sacrificed at 1, 3, 5, 7, 14 and 21 days after wounding and tissue samples were obtained from three different wounds at each time point. The animals were housed and used according to the Rules for the Care and Use of Laboratory Animal Guidelines of the Nippon Dental University under a protocol approved by the Institutional Review Board.

Immunostaining.Unstainedformalin-fixed,paraffin-embedded carcinoma and mouse wound sections were incubated with rabbit anti-FABP4 (ab13979; Abcam, Tokyo, Japan) or rat
anti-FABP5 (MAB3077; R\&D Systems, Minneapolis, MN, USA) antibodies followed by biotinylated anti-rabbit or -rat IgG . Following treatment with avidin-biotin complexes, the color was developed with 3,3'-diaminobenzidine hydrochloride. The immunostaining of FABPs was evaluated as described previously (20). Briefly, the extent of staining was scored on a scale of $0-4$ : 0 , totally negative; $1,<10 \% ; 2,10-40 \% ; 3,41-60 \%$; or $4,>61 \%$. Positive nuclear and/or cytoplasmic staining was subjectively classified as: 1 , weak; 2 , moderate; or 3 , strong at the area of strongest staining due to the variable intensity of the staining. Weak staining was barely discernible and only clearly visible on high-power examination; moderate staining was easily seen at low power and was light brown in color; and strong staining was intense and dark brown with a painted-on appearance. An immunohistochemical composite score was calculated by multiplying the extent and intensity scores to give a value of between $0-12$.

Statistical analysis. Pearson's Chi-square test was used to analyze the immunostaining score for clinicopathological parameters. The Wilcoxon signed-rank test was used to compare between the scores. $\mathrm{P}<0.05$ was considered to indicate a statistically significant difference. 


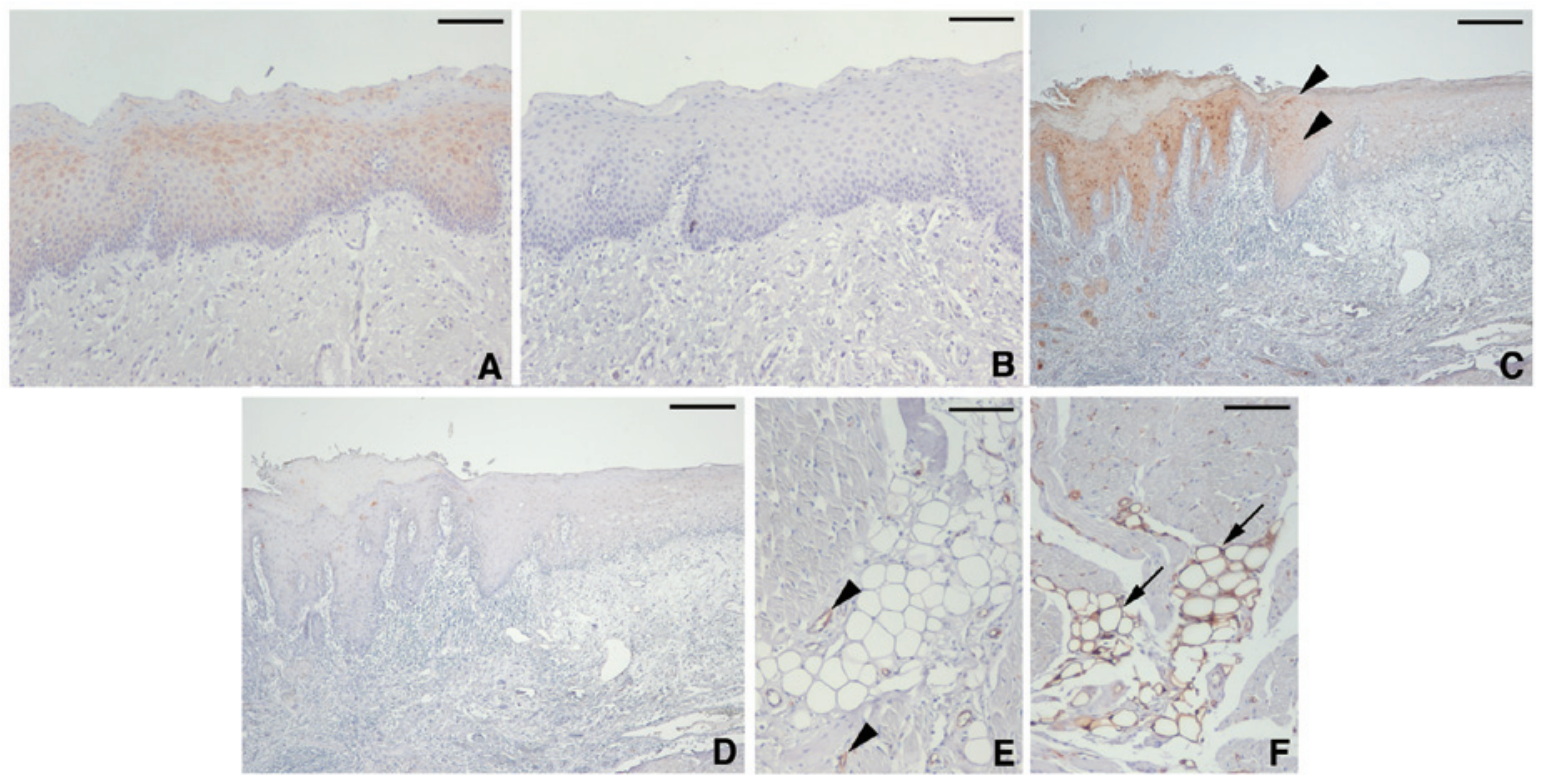

Figure 1. Fatty acid-binding protein (FABP) expression in normal and carcinoma-adjacent epithelium of the tongue. (A, C and E) FABP5 and (B, D and F) FABP4 were stained on (A and B) normal tongue epithelium and (C and D) epithelium interface with carcinomas. Epithelial cells adjacent to the carcinomas enhanced FABP5 staining (arrowheads). (E, arrowheads) FABP5 was stained at the endothelial cells and (F, arrows) FABP4 at adipocytes in dermis. Bar, (C and D) $100 \mu \mathrm{m}$ and (A,B,E and F) $40 \mu \mathrm{m}$.

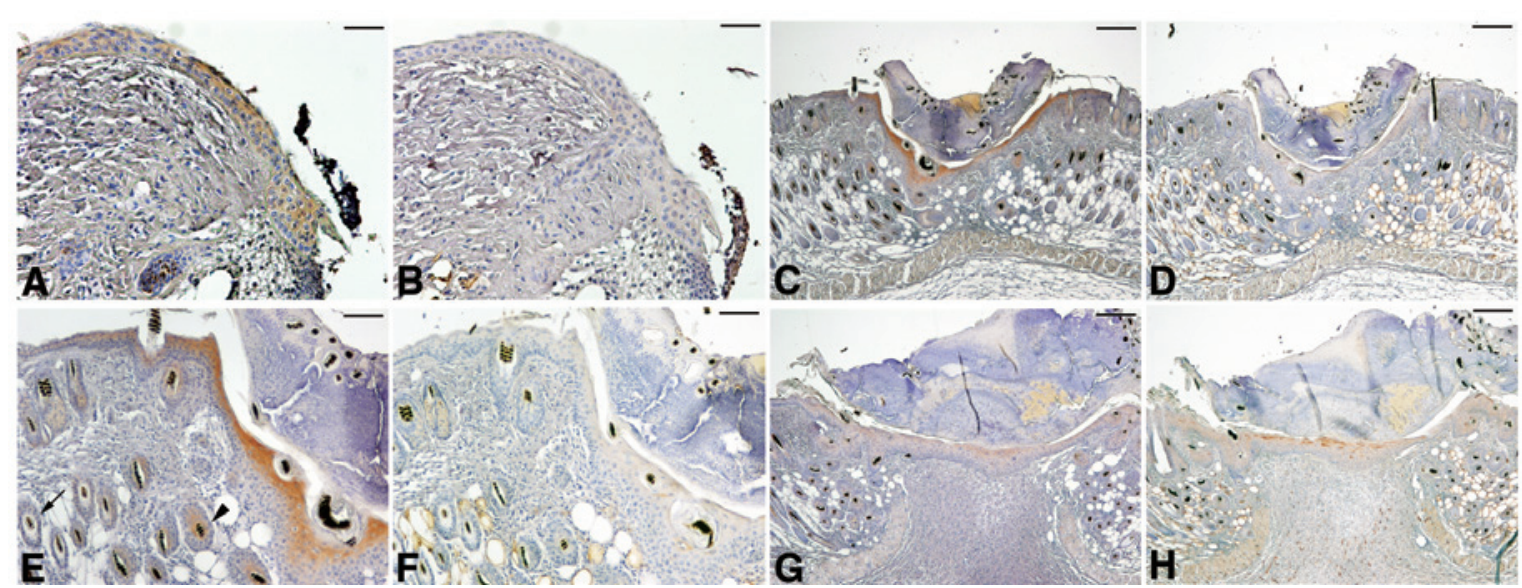

Figure 2. Fatty acid-binding protein (FABP) expression in skin wounds. (A, C, E and G) FABP5 and (B, D, F and H) FABP4 expression in mouse skin wounds at (A and B) day 1; (C-F) day 3; and (G and H) day 5 are shown. (E) The arrowhead and arrow show the hair follicle adjacent and far distal site of wounds, respectively. Bar, (C,D,G and $\mathrm{H}) 100 \mu \mathrm{m}$; (E and F) $40 \mu \mathrm{m}$; and (A and B) $20 \mu \mathrm{m}$.

\section{Results}

Expression and distribution of FABPs in a normal tongue. FABP5 expression was weakly detected at the cytoplasm of upper-suprabasal cells beneath the keratinized layer (Fig. 1A). FABP4 was not expressed in the normal epithelial cells of the tongue (Fig. 1B). At the epithelium, adjacent to carcinoma cells, FABP5-positive cells were extended to the suprabasal layer with a moderate-to-strong staining intensity (Fig. 1C), whereas FABP4 expression was negligible (Fig. 1D). The specificity of anti-FABP5 and -FABP4 antibodies was confirmed by the staining of endothelial cells (Fig. 1E) (21) and adipocytes (Fig. 1F) (8), respectively.

FABP expression in mouse skin wounds. The enhanced expression of FABP5 in the carcinoma-adjacent epithelium is suggestive of the fact that factors from the surrounding tissues or genetic alterations may activate FABP5 expression. Subsequently, FABP expression at the skin wounds of a genetically normal mouse was examined. As shown in Fig. 2, FABP5 expression was detected at the epithelial cells migrating on the wound surface at day 1 . It became prominent at the cytoplasm of suprabasal cells at day 3 and gradually declined thereafter. FABP4 expression was slightly detected in the epithelium at day 3 but was negatively expressed at the earlier and later epithelium. The restricted detection of FABP5 on the skin epithelium and the strong staining of FABP4 on the subcutaneous adipocytes confirmed the specificity of antibodies to mouse FABPs.

FABP5 expression in tongue carcinomas. FABP5 expression was detected in all carcinoma tissues. It was preferentially 
Table II. Fatty acid-binding protein 5 staining score in non-progressive/advanced stages of carcinomas.

\begin{tabular}{|c|c|c|c|c|c|}
\hline \multirow[b]{2}{*}{ Parameters } & \multirow[b]{2}{*}{ No. } & \multicolumn{2}{|c|}{ Nucleus } & \multicolumn{2}{|c|}{ Cytoplasm } \\
\hline & & Mean $\pm \mathrm{SD}$ & P-value ${ }^{a}$ & Mean \pm SD & $\mathrm{P}$-value ${ }^{\mathrm{a}}$ \\
\hline T-stage ${ }^{b}$ & & & 0.357 & & 0.041 \\
\hline $\mathrm{T} 1$ & 38 & $4.842 \pm 2.666$ & & $7.552 \pm 2.617$ & \\
\hline $\mathrm{T} 2-4$ & 20 & $5.421 \pm 3.061$ & & $9.368 \pm 2.948$ & \\
\hline N-stage ${ }^{b}$ & & & 0.355 & & 0.383 \\
\hline No & 49 & $5.021 \pm 2.809$ & & $7.979 \pm 2.780$ & \\
\hline N1-2 & 9 & $5.111 \pm 2.848$ & & $9.111 \pm 3.140$ & \\
\hline Clinical stage ${ }^{\mathrm{b}}$ & & & 0.357 & & 0.041 \\
\hline 1 & 38 & $4.842 \pm 2.666$ & & $7.553 \pm 2.617$ & \\
\hline $2-4$ & 20 & $5.421 \pm 3.061$ & & $9.364 \pm 2.948$ & \\
\hline Histological differentiation $^{c}$ & & & 0.277 & & 0.051 \\
\hline Well & 32 & $5.469 \pm 2.771$ & & $8.188 \pm 2.856$ & \\
\hline Less & 26 & $4.480 \pm 2.771$ & & $8.120 \pm 2.877$ & \\
\hline
\end{tabular}

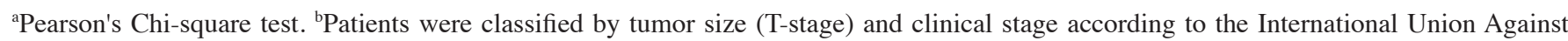
Cancer World Health Organization grading system and by the stage of lymph node metastasis (N-stage). ${ }^{c}$ Well, well-differentiated carcinomas; less, moderately and poorly differentiated carcinomas.

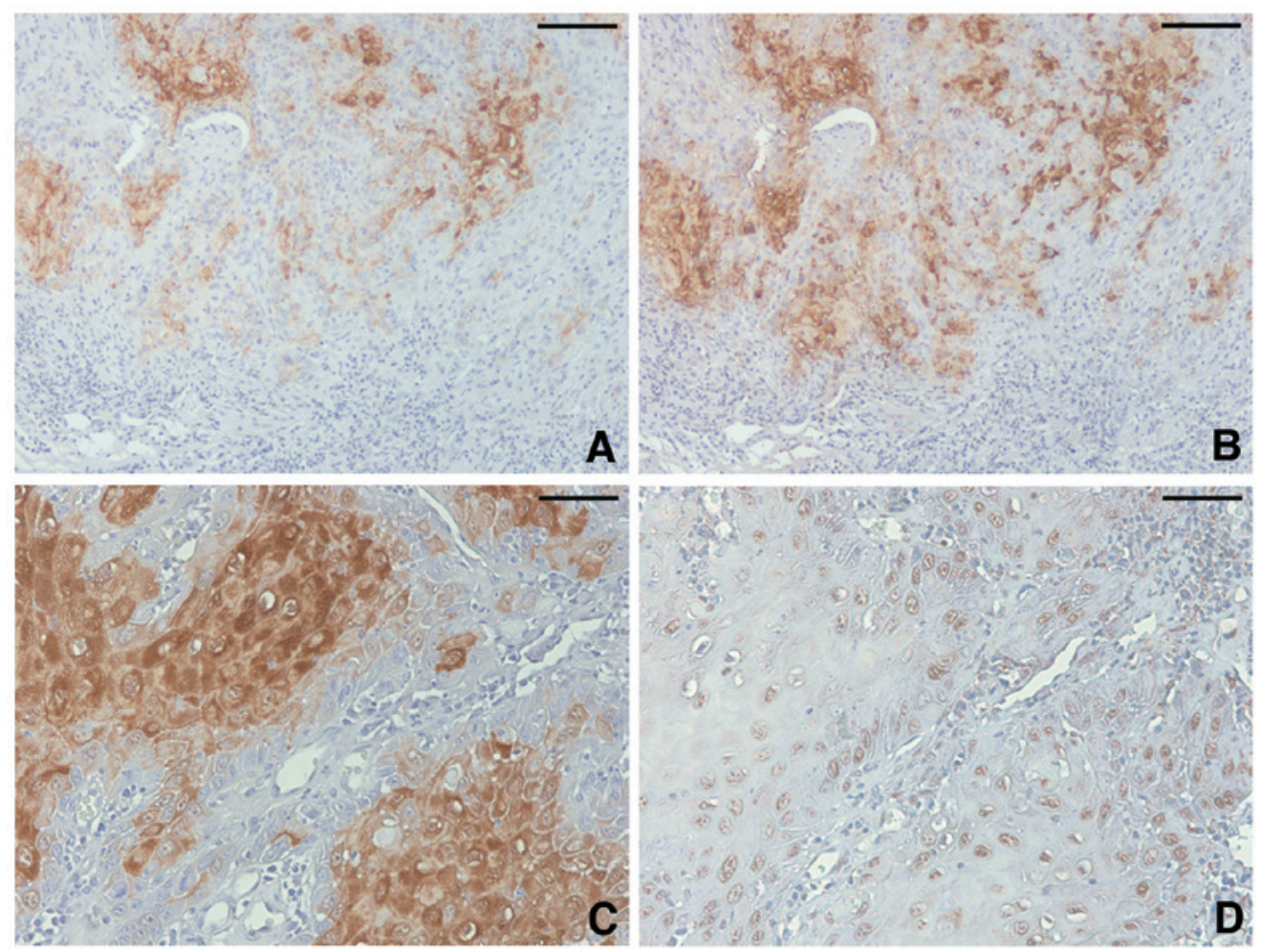

Figure 3. Fatty acid-binding protein (FABP) expression in tongue carcinomas. (A and C) FABP5 and (B and D) FABP4 were stained on the cytoplasm and/or nucleus of carcinoma cells. Bar, (A and B) $40 \mu \mathrm{m}$ and (C and D) $20 \mu \mathrm{m}$.

observed at the cytoplasm of carcinoma cells, particularly at the center of tumor cell nests (Fig. 3A and C). The nuclear staining was weak and less frequent (mean $\pm \mathrm{SD}, 5.035 \pm 2.790$ ) compared with the cytoplasmic staining $(8.158 \pm 2.840$, $\mathrm{P}<0.001)$. The percentage $(3.351 \pm 0.813)$ and staining intensity $(2.439 \pm 0.598)$ scores of the cytoplasm suggest that tongue carcinoma cells frequently express FABP5 at a moderate-to-high level.

The correlation of the FABP5 staining score with the clinicopathological parameters was statistically evaluated (Table I). Although no significant difference was observed between them, the score increased in the advanced stages of 
Table III. Fatty acid-binding protein 4 staining score and clinicopathological parameters.

\begin{tabular}{|c|c|c|c|c|c|}
\hline \multirow[b]{2}{*}{ Parameters } & \multicolumn{3}{|c|}{ Nucleus } & \multicolumn{2}{|c|}{ Cytoplasm } \\
\hline & No. & Mean \pm SD & P-value ${ }^{a}$ & Mean \pm SD & P-value ${ }^{a}$ \\
\hline Age (years) & & & 0.099 & & 0.194 \\
\hline$<65$ & 33 & $5.212 \pm 3.798$ & & $4.424 \pm 3.093$ & \\
\hline$\geq 65$ & 25 & $4.400 \pm 2.972$ & & $4.360 \pm 2.752$ & \\
\hline Gender & & & 0.266 & & 0.153 \\
\hline Female & 24 & $4.208 \pm 3.134$ & & $4.083 \pm 3.269$ & \\
\hline Male & 34 & $5.324 \pm 3.649$ & & $4.618 \pm 2.686$ & \\
\hline T-stage $\mathrm{e}^{\mathrm{b}}$ & & & 0.669 & & 0.852 \\
\hline $\mathrm{T} 1$ & 38 & $4.737 \pm 3.629$ & & $4.211 \pm 2.849$ & \\
\hline $\mathrm{T} 2$ & 18 & $4.833 \pm 3.222$ & & $4.722 \pm 3.268$ & \\
\hline $\mathrm{T} 4$ & 2 & $7.500 \pm 2.121$ & & $5.000 \pm 1.414$ & \\
\hline N-stage ${ }^{b}$ & & & 0.915 & & 0.527 \\
\hline N0 & 49 & $4.837 \pm 3.490$ & & $4.347 \pm 2.803$ & \\
\hline N1 & 6 & $3.333 \pm 1.751$ & & $4.000 \pm 4.336$ & \\
\hline $\mathrm{N} 2$ & 3 & $8.333 \pm 4.041$ & & $6.000 \pm 2.000$ & \\
\hline Clinical stage $^{b}$ & & & 0.979 & & 0.279 \\
\hline 1 & 38 & $4.734 \pm 3.629$ & & $4.211 \pm 2.849$ & \\
\hline 2 & 10 & $5.100 \pm 3.247$ & & $4.900 \pm 2.846$ & \\
\hline 3 & 6 & $3.333 \pm 1.751$ & & $4.000 \pm 4.336$ & \\
\hline 4 & 4 & $7.750 \pm 3.500$ & & $5.500 \pm 1.915$ & \\
\hline Histological differentiation & & & 0.695 & & 0.492 \\
\hline Well & 32 & $5.094 \pm 3.762$ & & $4.250 \pm 2.771$ & \\
\hline Moderate & 20 & $4.300 \pm 2.812$ & & $4.850 \pm 3.281$ & \\
\hline Poor & 6 & $5.500 \pm 4.087$ & & $3.667 \pm 2.733$ & \\
\hline
\end{tabular}

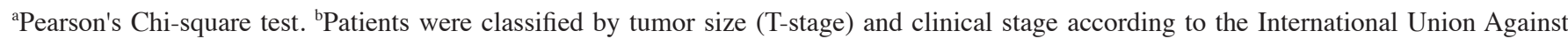
Cancer World Health Organization grading system and by stage of lymph node metastasis (N-stage).

the carcinomas. A number of observations at each stage of the parameters were variable, thus we divided patients into the advanced and non-advanced groups. The advanced group on the $\mathrm{T}$ - and clinical stages exhibited a significantly higher score compared with the non-advanced group (Table II).

FABP4 expression in tongue carcinomas. FABP4-positive cells are distributed randomly through carcinoma tissues and frequently located at peripheries of tumor cell nests where FABP5 staining was rapidly reduced (Fig. 3B). The percentage score of FABP4 cytoplasm-positive cells $(2.368 \pm 1.057)$ and the staining intensity score $(1.776 \pm 0.750)$ were low compared wiht that of FABP5 (percentage score, $3.351 \pm 0.813, \mathrm{P}<0.001$; staining intensity score, $2.439 \pm 0.598$, $\mathrm{P}<0.001)$. Although the percentage and intensity of FABP4 nuclear staining was comparable with FABP5 (data not shown), FABP4 was frequently localized at the nucleus without the cytoplasmic staining (Fig. 3D). This exclusive nuclear staining was not observed in the FABP5 staining. No statistical difference was observed in the nuclear and cytoplasmic score for any of the clinicopathological parameters (Table III).

\section{Discussion}

FABPs transport LCFAs to the proper cell compartments and play a multifaceted role, particularly for lipid storage and $\beta$-oxidation in the cytoplasm and for transcription factor activation in the nucleus $(8,9)$. Although FABP expression is restricted within the originally identified tissues, findings of a previous study emphasized that the aberrant expression is involved in carcinoma progression (8). In this study, we examined FABP4 and FABP5 expression in tongue carcinomas and identified a correlation between cytoplasmic FABP5 staining and disease progression.

The enhanced expression of FABP5 in epithelial cells at the skin wound edge and near carcinoma cells confirmed the findings of previous studies $(22,23)$. Epithelial cells at the wound edge stimulate metabolic pathways (24) and its rapid proliferation and migration are key features in the early phase of wound healing $(25,26)$. FABP5 is overexpressed in proliferating keratinocytes (27) and stimulates the proliferation and migration of oral carcinoma cells (11). Although the staining intensity was not strong, FABP5 expression was detected in wounds at day 1 , suggesting the involvement of FABP5 in the 
early phase of wound coverage. However, FABP5 promotes keratinocyte differentiation (28), as was evident by strong staining in the keratinizing suprabasal cells of wounded epithelium at day 3. These data confirmed the data of a previous study which demonstrated that FABP5 is markedly expressed in post-mitotic skin keratinocytes and weakly detectable in proliferating keratinocytes (29). Differentiating keratinocytes do not reside in the proliferation cycle (30). These paradoxical events suggest a multifaceted role and/or a biphasic action of FABP5 in the definition of cells depending on the situation.

The majority of cells positioned at or near carcinomas are associated with genetic alterations (31). The transient expression of FABP5 in the wounded skin of a genetically normal mouse indicates that epithelial cells upregulate FABP5 expression as a result of tissue reaction. This finding was supported by the intense staining at hair follicle cells near the wounds compared with the far distal follicle cells. It seems likely that carcinoma cells and the juxtaposed epithelial cells initiate the expression under the tissue reaction. Epidermal growth factor, a representative tissue factor, facilitates carcinoma progression (4) and skin wound healing (32) and overexpresses FABP5 (33). Other growth factors such as WNT and transforming growth factor- $\beta$, which stimulate progression and healing $(34,35)$ regulate FABP5 expression $(36,37)$. Since proteolytic degradation of the extracellular matrix releases growth factors (38), we should consider the impact of carcinoma cell-tissue interactions on the expression carefully. Furthermore, an intracellular signaling molecule, mucosa-associated lymphoid tissue 1, which suppresses the aggressive phenotype of oral carcinoma cells and is inactivated in the patients with worse prognosis directly affects FABP expression $(39,40)$. Therefore both genetic and environmental factors provoke carcinoma cells to express FABP5.

The cytoplasmic FABP5 staining score was increased in carcinomas with the advanced $\mathrm{T}$ - and clinical stages in the current study. FABP5 transports LCFAs to mitochondria for energy production $(8,9)$ and the increased production strongly facilitates the aggressive properties of carcinoma cells (7). Carcinoma progression (clinical stage) is a comprehensive issue evaluated by tumor expansion (T-stage) and metastasis (N-and M-stage). Since carcinoma metastasis is a consequence of various phenomena (4), the insignificance of expression in $\mathrm{N}$-stage is unlikely to negate the role of FABP5 in carcinoma aggressiveness. Enhanced energy production by FABP5 may result in the rapid proliferation of carcinoma cells and tumor expansion.

The pathological role of FABP4 is largely different among carcinomas, as it is suppressive in bladder $(17,41)$ and breast carcinomas (18) and stimulatory in gastric (14) and ovarian carcinomas (15). FABP4 expression was identified in almost all the tongue carcinomas examined. Although it was undetected in the normal epithelium, it is expressed by the suprabasal cells of wounded skin epithelium at day 5, although not the earlier and later wounds. This observation suggests that the expression in keratinocytes is not largely regulated by tissue factors. The FABP4 staining score did not correlate with oral carcinoma progression in the current study. FABP4, unlike FABP5, was frequently localized at the nucleus without the cytoplasmic staining. FABP4 transports LCFAs to the nucleus, which is required for stable binding with peroxisome-proliferator-activated receptor (PPAR)- $\gamma$. PPAR- $\gamma$ expression in tongue carcinomas is higher in patients with an improved prognosis (42) and the administration of a PPAR- $\gamma$ agonist inhibits the development of tongue carcinoma (43). However, oral carcinoma cells showing aggressive phenotypes in vitro strongly upregulate FABP4 expression $(40,44)$. Detailed future studies are required in order to further clarify the role of ectopic expression.

FABP5 was mainly detected at the cytoplasm that was prominent in advanced tongue carcinomas. Enhanced expression may contribute to the production of sufficient quantities of energy that result in the progression of carcinomas to a more advanced stage. Identification of the mechanism of FABP5 upregulation and the pathological role in detail should therefore be analyzed for in order to improve patient prognosis.

\section{Acknowledgements}

This study was supported by an institutional grant from the Nippon Dental University (to K.I.) and by grants from JSPS KAKENHI (no. 22592080, to T.C.) and (no. 22592103, to K.I.); and based on a partial fulfillment of doctoral thesis submitted to the Graduate School of Dentistry, Meikai University, in partial fulfillment of the requirements for the Doctor of Dental Surgery degree.

\section{References}

1. Regezi JA, Sciubba JJ and Jordan RCK (eds): Oral Pathology: Clinical Pathologic Correlations. 5th edition. Saunders-Elsevier, Philadelphia, PA, pp 552-556, 2008.

2. Ariyoshi Y, Shimahara M, Omura K, Yamamoto E, Mizuki H, Chiba H, Imai Y, Fujita S, Shinohara M, Seto K and Japanese Society of Oral and Maxillofacial Surgeons: Epidemiological study of malignant tumors in the oral and maxillofacial region: survey of member institutions of the Japanese Society of Oral and Maxillofacial Surgeons, 2002. Int J Clin Oncol 13: 220-228, 2008.

3. Choi S and Myers JN: Molecular pathogenesis of oral squamous cell carcinoma: implications for therapy. J Dent Res 87: 14-32, 2008.

4. Hanahan D and Weinberg RA: Hallmarks of cancer: the next generation. Cell 144: 646-674, 2011.

5. Cairns RA, Harris IS and Mak TW: Regulation of cancer cell metabolism. Nat Rev Cancer 11: 85-95, 2011.

6. Fuchs E: Epidermal differentiation: the bare essentials. J Cell Biol 111: 2807-2814, 1990.

7. Ward PS and Thompson CB: Metabolic reprogramming: a cancer hallmark even Warburg did not anticipate. Cancer Cell 21: 297-308, 2012.

8. Furuhashi $\mathrm{M}$ and Hotamisligil GS: Fatty acid-binding proteins: role in metabolic diseases and potential as drug targets. Nat Rev Drug Discov 7: 489-503, 2008.

9. Smathers RL and Petersen DR: The human fatty-acid binding protein family: evolutionary divergences and functions. Hum Genomics 5: 170-191, 2011.

10. Siegenthaler G, Hotz R, Chatellard-Gruaz D, Jaconi S and Saurat JH: Characterization and expression of a novel human fatty acid-binding protein: the epidermal type (E-FABP). Biochem Biophys Res Commun 190: 482-487, 1993.

11. Fang LY, Wong TY, Chiang WF and Chen YL: Fatty-acid-binding protein 5 promotes cell proliferation and invasion in oral squamous cell carcinoma. J Oral Pathol Med 39: 342-348, 2010.

12. Melle C, Ernst G, Winkler R, Schimmel B, Klussmann JP, Wittekindt C, Guntinas-Lichius O and von Eggeling F: Proteomic analysis of human papillomavirus-related oral squamous cell carcinoma: identification of thioredoxin and epidermal-fatty acid binding protein as upregulated protein markers in microdissected tumor tissue. Proteomics 9: 2193-2201, 2009.

13. Uma RS, Naresh KN, D'Cruz AK, Mulherkar R and Borges AM: Metastasis of squamous cell carcinoma of the oral tongue is associated with down-regulation of epidermal fatty acid binding protein (E-FABP). Oral Oncol 43: 27-32, 2007. 
14. Hashimoto T, Kusakabe T, Sugino T, Fukuda T, Watanabe K, Sato Y, Nashimoto A, Honma K, Kimura H, Fujii H and Suzuki T: Expression of heart-type fatty acid-binding protein in human gastric carcinoma and its association with tumor aggressiveness, metastasis and poor prognosis. Pathobiology 71: 267-273, 2004.

15. Nieman KM, Kenny HA, Penicka CV, Ladanyi A, Buell-Gutbrod R, Zillhardt MR, Romero IL, Carey MS, Millis GB, Hotamisligil GS, et al: Adipocytes promote ovarian cancer metastasis and provide energy for rapid tumor growth. Nat Med 17: 1498-1503, 2011.

16. Celis JE, Ostergaard M, Basse B, Celis A, Lauridsen JB, Ratz GP, Andersen I, Hein B, Wolf H, Orntoft TF and Rasmussen HH: Loss of adipocyte-type fatty acid binding protein and other protein biomarkers is associated with progression of human bladder transitional cell carcinomas. Cancer Res 56: 4782-4790, 1996.

17. Boiteux G, Lascombe I, Roche E, Plissonnier ML, Clairotte A, Bittard $\mathrm{H}$ and Fauconnet S: A-FABP, a candidate progression marker of human transitional cell carcinoma of the bladder, is differentially regulated by PPAR in urothelial cancer cells. Int J Cancer 124: 1820-1828, 2009.

18. Hammamieh R, Chakraborty N, Barmada M, Das R and Jett M: Expression patterns of fatty acid binding proteins in breast cancer cells. J Exp Ther Oncol 5: 133-143, 2005.

19. Okuse T, Chiba T, Katsuumi I and Imai K: Differential expression and localization of WNTs in an animal model of skin wound healing. Wound Repair Regen 13: 491-497, 2005.

20. McCluggage WG, Connolly LE, McBride HA, Kalloger S and Gilks CB: HMGA2 is commonly expressed in uterine serous carcinomas and is a useful adjunct to diagnosis. Histopathology 60: 547-553, 2012.

21. Masouye I, Hagens G, Van Kuppevelt TH, Madsen P, Saurat JH, Veerkamp JH, Pepper MS and Siegenthaler G: Endothelial cells of the human microvasculature express epidermal fatty acid-binding protein. Circ Res 81: 297-303, 1997

22. Kusakari Y, Ogawa E, Owada Y, Kitanaka N, Watanabe H, Kimura M, Tagami H, Kondo H, Aiba S and Okuyama R: Decreased keratinocyte motility in skin wound on mice lacking the epidermal fatty acid binding protein gene. Mol Cell Biochem 284: 183-188, 2006

23. Han J, Kioi M, Chu WS, Kasperbauer JL, Strome SE and Puri RK: Identification of potential therapeutic targets in human head and neck squamous cell carcinoma. Head Neck Oncol 1: 27, 2009.

24. Chi C and Trinkaus-Randall V: New insights in wound response and repair of epithelium. J Cell Physiol 228: 925-929, 2013.

25. Martin P: Wound healing - aiming for perfect skin regeneration. Science 276: 75-81, 1997 .

26. Singer AJ and Clark RA: Cutaneous wound healing. N Engl J Med 341: 738-746, 1999.

27. Ogawa E, Owada Y, Ikawa S, Adachi Y, Egawa T, Nemoto K, Suzuki K, Hishinuma T, Kawashima H, Kondo $\mathrm{H}$, et al Epidermal FABP (FABP5) regulates keratinocyte differentiation by $13(\mathrm{~S})-\mathrm{HODE}-$ mediated activation of the NF- $\mathrm{BB}$ signaling pathway. J Invest Dermatol 131: 604-612, 2011.

28. Hagens G, Masouye I, Augsburger E, Hotz R, Saurat JH and Siegenthaler G: Calcium-binding protein S100A7 and epidermal-type fatty acid-binding protein are associated in the cytosol of human keratinocytes. Biochem J 339: 419-427, 1999.

29. Dallaglio K, Marconi A, Truzzi F, Lotti R, Palazzo E, Petrachi T, Saltari A, Coppini M and Pincelli C: E-FABP induces differentiation in normal human keratinocytes and modulates the differentiation process in psoriatic keratinocytes in vitro. Exp Dermatol 22: 255-261, 2013.
30. Gandarillas A: The mysterious human epidermal cell cycle, or an oncogene-induced differentiation checkpoint. Cell Cycle 11: 4507-4516, 2012

31. Ashida S, Orloff MS, Bebek G, Zhang L, Zheng P, Peehl CM and Eng $C$ : Integrated analysis reveals critical genomic regions in prostate tumor microenvironment associated with clinicopathologic phenotypes. Clin Cancer Res 18: 1578-1587, 2012.

32. Shirakata Y, Kimura R, Nanba D, Iwamoto R, Tokumaru S, Morimoto C, Yokota K, Nakamura M, Sayama K, Mekada E, et al: Heparin-binding EGF-like growth factor accelerates keratinocyte migration and skin wound healing. J Cell Sci 118: 2363-2370, 2005.

33. Kannan-Thulasiraman P, Seachrist DD, Mahabeleshwar GH, Jain MK and Noy N: Fatty acid-binding protein 5 and PPAR- $\beta / \delta$ are critical mediators of epidermal growth factor receptor-induced carcinoma cell growth. J Biol Chem 285: 19106-19115, 2010.

34. Uraguchi M, Morikawa M, Shirakawa M, Sanada K and Imai K: Activation of WNT family expression and signaling in squamous cell carcinomas of the oral cavity. J Dent Res 83: 327-332, 2004

35. Bielefeld KA, Amini-Nik S and Alman BA: Cutaneous wound healing: recruiting developmental pathways for regeneration. Cell Mol Life Sci 70: 2059-2081, 2013.

36. Collins CA and Watt FM: Dynamic regulation of retinoic acid-binding proteins in developing, adult and neoplastic skin reveals roles for beta-catenin and Notch signalling. Dev Biol 324: 55-67, 2008.

37. Knoferle J, Ramljak S, Koch JC, Tonges L, Asif AR, Michel U, Wouters FS, Heermann S, Krieglstein K, Zerr I, et al: TGF-beta 1 enhances neurite outgrowth via regulation of proteasome function and EFABP. Neurobiol Dis 38: 395-404, 2010.

38. Imai K, Hiramatsu A, Fukushima D, Pierschbacher PD and Okada Y: Degradation of decorin by matrix metalloproteinases: identification of the cleavage sites, kinetic analyses and transforming growth factor-beta1 release. Biochem J 322: 809-814, 1997.

39. Chiba T, Maeda G, Kawashiri S, Kato K and Imai K: Epigenetic loss of mucosa-associated lymphoid tissue 1 expression in patients with oral carcinomas. Cancer Res 69: 7216-7223, 2009.

40. Ohyama Y, Kawamoto Y, Chiba T, Maeda G, Sakashita H and Imai K: Inhibition of TGF- $\beta$ and EGF pathway gene expression and migration of oral carcinoma cells by mucosa-associated lymphoid tissue 1. Br J Cancer 109: 207-214, 2013.

41. Tuncman G, Erbay E, Hom X, De Vivo I, Campos H, Rimm EB and Hotamisligil GS: A genetic variant at the fatty acid-binding protein aP2 locus reduces the risk for hypertriglyceridemia, type 2 diabetes, and cardiovascular disease. Proc Natl Acad Sci USA 103: 6970-6975, 2006.

42. Theocharis S, Klijanienko J, Giaginis C, Rodriguez J, Jouffroy T, Girod A, Point D, Tsourouflis G and Satre-Garau X: Peroxisome proliferator-activated receptor- $\gamma$ in mobile tongue squamous cell carcinoma: associations with clinicopathological parameters and patients survival. J Cancer Res Clin Oncol 137: 251-259, 2011.

43. Yoshida K, Hirose Y, Tanaka T, Yamada Y, Kuno T, Kohno H, Katayama H, Qiao Z, Sakata K, Sugie S, et al: Inhibitory effects of troglitazone, a peroxisome proliferator-activated receptor $\gamma$ ligand, in rat tongue carcinogenesis initiated with 4-nitroquinoline 1-oxide. Cancer Sci 94: 365-371, 2003.

44. Kawamoto Y, Ohyama Y, Chiba T, Yagishita H, Sakashita H and Imai K: Proteomic identification of keratin alterations with enhanced proliferation of oral carcinoma cells by loos of mucosa-associated lymphoid tissue 1 expression. Int J Oncol 43, 729-736, 2013 